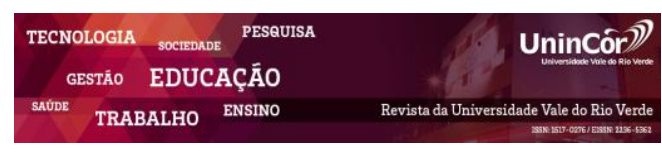

Revista da Universidade Vale do Rio Verde ISSN: 1517-0276 / EISSN: 2236-5362 v. $17 \mid$ n. 1 | Ano 2019

Jhuly Martins Magalhães Universidade Vale do Rio Verde - UninCor magalhaesjhuly@gmail.com

Doge Palhares Júnior Universidade Vale do Rio Verde - UninCor prof.doge.palhares@unincor.edu.br

Sérgio Ricardo Silva Magalhães Universidade Vale do Rio Verde - UninCor sergio.magalhaes@unincor.edu.br

Letícia Rodrigues da Fonseca Universidade Vale do Rio Verde - UninCor leticia.rodrigues.vga@gmail.com

Dejanir José Campos Júnior Universidade Vale do Rio Verde - UninCor dejanir.junior@unincor.edu.br

Zelma Leal da Paixão Silva Universidade Vale do Rio Verde - UninCor zelmaleal@gmail.com

Paola da Silva Vieira

Universidade Vale do Rio Verde - UninCor paola.diniz@unincor.edu.br

\section{LOGÍSTICA ESTRATÉGICA: A CADEIA DE SUPRIMENTOS NA PERSPECTIVA DE FUTURO DE UMA ORGANIZAÇÃO}

\section{RESUMO}

Esse trabalho enfatiza o planejamento estratégico organizacional, levando-se em conta o tripé da sustentabilidade: Social, Ambiental e Financeiro (Triple Bottom Line), de modo a evidenciar as melhores práticas para uma Logística Enxuta, alinhada a decisões firmes e acertadas em toda a Cadeia de Suprimento (Supply Chain). No universo empresarial, o planejamento estratégico deve ser prioridade para o alcance dos objetivos da organização norteando caminhos para as tomadas de decisões eficazes, além de orientar para o aproveitamento de todos os recursos a se utilizar. Existem muitas organizações que ainda não fazem um planejamento estratégico e uma logística estratégica, seja pela complexidade dessa ferramenta, ou mesmo pela ineficiência de gestão da organização. O objetivo desse trabalho de pesquisa cientifica foi de o evidenciar a necessidade das organizações se preparem para o futuro, a partir de um planejamento estratégico fundamentado. Isso irá auxiliar as empresas em suas tomadas de decisões, tornando todo o processo mais produtivo, no que diz respeito a logística e toda a cadeia de suprimentos, facilitando e norteando sua visão quanto ao seus planejamentos e planos futuros. A pesquisa em tese demonstrou a importância de se aplicar um planejamento estratégico em uma organização, diante dos desígnios empresarias, e a facilidade de implementação de projetos estratégicos, quanto a sua importância, levando-se em conta a preocupação, não apenas com a obtenção de lucro, mas também com a sociedade e o meio ambiente, onde a mesma está inserida. Nesse contexto, se aplicados a presente pesquisa, conforme se recomenta, mais facilidade terá a organização para se adequar ao mercado e desenvolver seus planos traçados, de modo a garantir seu futuro junto as demais organizações, garantindo dessa forma sua sobrevivência, diante de um mercado competitivo e com clientes cada vez mais exigentes.

Palavras-chave: Logística estratégica, Plano de negócio e Planejamento empresarial.

\section{STRATEGIC LOGISTICS: THE SUPPLY CHAIN IN THE A FUTURE PERSPECTIVE OF AN ORGANIZATION}

\begin{abstract}
This work emphasizes organizational strategic planning, taking into account the tripod of sustainability: Social, Environmental and Financial (Triple Bottom Line), in order to highlight the best practices for Lean Logistics, in line with firm and sound decisions throughout Supply Chain. In the business world, strategic planning must be a priority for the achievement of the organization's objectives, guiding paths to effective
\end{abstract}


decision-making, and guiding the use of all the resources to be used. There are many organizations that do not yet make strategic planning and strategic logistics, either because of the complexity of that tool or even because of the organization's inefficiency of management. The objective of this scientific research work was to show the need for organizations to prepare for the future, based on a well-founded strategic planning. This will help companies in their decision making, making the whole process more productive, in terms of logistics and the entire supply chain, facilitating and guiding their vision of their future plans and plans. The research in thesis has demonstrated the importance of applying a strategic planning in an organization, in front of the entrepreneurial designs, and the ease of implementation of strategic projects, as to its importance, taking into account the concern, not only with obtaining profit, but also with society and the environment, where it is inserted. In this context, if applied to this research, as it is recommended, it will be easier for the organization to adapt to the market and develop its plans, so as to guarantee its future with the other organizations, thus guaranteeing its survival, in front of a market competitive and with increasingly demanding customers.

Keywords: Strategic Logistics, Business Plan and Business Planning.

Recebido em: 10/11/2018 - Aprovado em:11/04/2019 - Disponibilizado em: 15/07/2019

\section{INTRODUÇÃO}

O mercado cresce gradativamente, diante de um contexto competitivo, cada vez mais acirrado. $\mathrm{O}$ avanço tecnológico e a concorrência ampla, faz com que cada vez mais os consumidores optem por bens e serviços de qualidade e com custos menores. Essa realidade faz com que os negócios empresariais sejam a cada dia repensados em curto, médio e longo prazos, pois a permanência nesse cenário depende de estratégias bem definidas e alinhadas em todos os aspectos dentro e fora do ambiente organizacional

Para o sucesso empresarial, as organizações devem priorizar modelos distintos de gestão, o qual seja condizente com a realidade mercadológica ao avaliar qual é o comportamento que seu cliente e seus consumidores imprimem em suas constantes buscas por qualidade, alinhada a preços competitivos, que permitam maior economia e maiores ganhos, pois sabe-se que a lucratividade se inicia no momento de aquisição, da compra.

Questões que envolvem novos estudos, pesquisas e projetos, difundem-se através dos gestores de muitas organizações com o pleito de maiores lucratividades e rentabilidade empresarial. Nesse contexto o planejamento estratégico, permite que a visibilidade de negócios duradouros, com alta longevidade possa estabelecer parâmetros que viabilize um posicionamento de mercado que permita o alcance de objetivos centrados na progressão sistemática de conquista desses mercados, tanto consumidor e fornecedor, quanto o mercado concorrente, com foco neste último.

O presente trabalho teve como objetivo, evidenciar a necessidade das organizações a se preparem para o futuro, justificando-se em seu 
aspecto teórico conceitual pela implementação de estratégia empresarial em seu escopo, o que deverá levar essas empresas a serem longevas, a partir da observação dos aspectos que envolvem a sustentabilidade em suas três dimensões, a saber: Social, Ambiental e Financeira (Triple Bottom Line).

É pelo Planejamento Estratégico que se define o caminho a seguir com foco no longo prazo da empresa. Nesta etapa que precisa-se buscar uma visão holística da organização sem entrar muito em detalhes, pois afinal, o Planejamento Estratégico geralmente é feito para um período de 5 a 10 anos e seria bastante complicado e pouco provável acertar tantos detalhes para um período tão futuro.

\section{METODOLOGIA}

Trata-se de pesquisa descritiva. A descrição do que é e para que serve a pesquisa bibliográfica permite compreender que, se de um lado a resolução de um problema pode ser obtida através dela, por outro, tanto a pesquisa de laboratório quanto a de campo (documentação direta) exigem, como premissa, o levantamento do estudo da questão que se propõe a analisar e solucionar. A pesquisa bibliográfica pode, portanto, ser considerada também como o primeiro passo de toda a pesquisa científica (MARCONI E LAKATOS, 2001). Com abordagem qualitativa, que segundo Minayo (1995, p 21-22), responde a questões muito particulares. Ela se preocupa nas ciências sociais, com um nível de realidade que não pode ser quantificado. Sua natureza é descritiva, pois exige do investigador uma série de informações sobre o que deseja pesquisar. Esse tipo de estudo pretende descrever os fatos e fenômenos de determinada realidade (TRIVIÑOS, 1987).

\section{REFERENCIAL TEÓRICO}

\subsection{GESTÃO EMPREENDEDORA E INOVAÇÃO NAS ORGANIZAÇÕES}

O conceito de "empreendedorismo" foi popularizado pelo economista Joseph Schumpeter em 1945, e a sua teoria teve como base a Destruição Criativa, conceito firmado por ele onde descreve o processo de inovação, em que novos produtos destroem empresas velhas e modelos antigos de negócios. Schumpeter ainda cita que o processo de destruição criativa é o fato essencial do capitalismo.

Para Schumpeter, o empreendedor é alguém versátil que tem habilidades técnicas para produzir e ser capitalista, conseguindo reunir recursos financeiros, organizar operações internas e realizar as vendas de sua empresa.

\subsection{PLANEJAMENTO ESTRATÉGICO}

Um elemento chave da estratégia é a seleção de algumas características e medidas que devem ser tomadas, de modo a atender a missão e a visão empresarial, pois, é através dessas, que se direcionam os gestores, administradores e todos os envolvidos na organização de modo compartilhado

Segundo Mintzberg, Ahlstrand e Lampel (2006) "Estratégia é um padrão, isto é, consistência em comportamento ao longo do tempo". As pessoas provavelmente diriam que 
estratégia seria um plano ou um planejamento uma direção, um guia ou curso de ação futuro, um caminho para ir de um lugar a outro... Mintzberg et al (2006). A julgar por essa concepção se todos os atores que desejam realizar um empreendimento tivessem esse entendimento, certamente o sucesso seria a magnificência das organizações.

Em outra concepção, Gerber (2004, p. 98) explana sobre o que vem a ser objetivo estratégico: Seu objetivo estratégico é uma declaração bastante clara do que sua empresa precisa fazer para alcançar o Objetivo Primário: é a visão do produto acabado que é e como será a empresa.

Compreender o que é estratégia e seu significado na organização não significa ditar conceitos e criar definições, mas de entender que se trata de um processo interativo entre as pessoas, ambiente, organização e planejamento que tem grande importância praticá-la socialmente como um todo (WHITTINGTON 2004).

Rêgo, Valadão Jr. e Souza (2013) relatam que: Uma vez que os projetos decorrem do desdobramento ou direcionamento estratégico, esses estão inter-relacionados e, portanto, justifica a importância de práticas formais para a seleção e priorização do portfólio de projetos. A abordagem prática da estratégia evidencia esta inter-relação, ao passo que os projetos são compreendidos como um processo que envolve a interação social.

Gerber (2004) expõe, "Todos querem 'se organizar', mas quando você sugere que eles iniciem criando um Gráfico da Organização, tudo o que você recebe são olhares de dúvida e, às vezes, de hostilidade".

\subsection{LOGÍSTICA ESTRATÉGICA}

A estratégia na logística reside no fato de se alcançar meios que proporcionem o atendimento global da demanda, nos menores custos e prazos possíveis.

Ballou (2009) conceitua logística empresarial como uma solução para os problemas, identificando o planejamento, a melhora e a facilidade com que as atividades são desempenhadas visando o lucro. Significa que a logística empresarial nasce para satisfazer o cliente e consequentemente para atingir $o$ sucesso da empresa. [...] a logística empresarial estuda como a administração pode prover melhor nível de rentabilidade nos serviços de distribuição aos clientes e consumidores, através de planejamento, organização e controle efetivos para as atividades de movimentação e armazenagem que visam facilitar o fluxo de produtos. (BALLOU, 2009, p.17).

Conforme Novaes (2007) o que faz com que o trabalho logístico se torne mais estimulante é a abundância de tarefas que todas essas áreas oferecem e, quando combinadas, tornam o gerenciamento integrado da logística uma profissão desafiante e compensadora.

Kotler (2006) descreve quatro importantes decisões que devem ser tomadas em relação a melhor estratégia logística de mercado: (1) processamento de pedidos, (2) armazenagem dos estoques, (3) estocagem e (4) como os produtos deverão ser transportados. 


\subsection{GESTÃO ESTRATÉGICA}

Logística é uma especialidade da administração responsável por prover recursos equipamentos e informações para a execução de todas as atividades de uma empresa. A logística busca otimizar todos os fluxos de informações e materiais, desde o ponto de origem até o seu ponto final, visando proporcionar níveis de serviços adequados aos seus clientes, com um preço competitivo (CARVALHO 2002, p.31).

Pires (2004) cita que o papel da logística no cenário nacional mudou nas últimas décadas e afirma que a percepção de realizar os processos logísticos de maneira certa agrega grande valor ao serviço / produto final.

A logística empresarial estuda como a administração pode prover melhor os níveis no serviço de distribuição aos clientes e fornecedores, através do planejamento, organização, e controle efetivos para as atividades de movimentação e armazenagem, para facilitar o fluxo de produtos.

Pozo (2001) destaca a importância do sistema de distribuição de cargas, em diversos pontos. $\mathrm{O}$ mesmo afirma que o impacto financeiro que o sistema de transporte em uma empresa é grande, sendo um dos pontos mais importantes dentro de uma cadeia de suprimentos.

Segundo Slack (1996), existem cinco tipos de transporte disponíveis para a distribuição física dos produtos de uma empresa: o transporte rodoviário, hidroviário, ferroviário, aéreo e os dutos.

Novaes (2004) também cita estes transportes como sendo os mais utilizados nos centros industriais do mundo, e explica que em alguns casos, utiliza-se mais de um meio de transporte para a carga chegar ao cliente.

É necessário estar atento a alguns problemas que surgem na logística, pois a distribuição de carga deve ser eficiente, buscando atender da melhor forma o seu cliente, oferecendo o melhor modal a ser escolhido para o seu atendimento.

\subsection{SUSTENTABILIDADE EMPRESARIAL}

O conceito de sustentabilidade tem sua origem nas disciplinas de Ética Empresarial e Economia Ambiental embora sua origem possa ser datada desde 1100 a 770 a.C., na China, através de leis que recomendavam a preservação das florestas.

Hart e Milstein (2004, p.65), sobre a questão da sustentabilidade, argumentam que após o fim do comunismo, o capitalismo tornouse a ideologia econômica dominante. Essa mudança trouxe "saturação dos mercados desenvolvidos, a ampliação do fosso entre ricos e pobres, o crescimento dos níveis de degradação ambiental" além da preocupação com a densidade populacional. "A sustentabilidade global parte do princípio que a satisfação das necessidades básicas da população, no presente, não deve comprometer a satisfação das necessidades das futuras gerações". E, ainda para Hart e Milstein (2004, p.66) o desenvolvimento sustentável deve procurar também o desenvolvimento humano e ao se tratar de uma empresa sustentável, essa deve gerar "simultaneamente benefícios econômicos, 
sociais e ambientais - conhecidos como os três pilares do desenvolvimento sustentável".

Figge et al. (2002, tradução nossa) relatam que os sistemas econômicos são refletidos pelos preços de mercado e que as questões sociais e ambientais, no entanto, refletem parcialmente embora se tornem cada vez mais importante para o negócio. Na última década medidas relacionadas às questões ambientais e sociais refletiram nas transações econômicas de preços de mercado provocando sua retração. Dessa forma, observou-se uma crescente preocupação quanto às questões ambientais e sociais, fazendo com que instrumentos de gestão pudessem amenizar esse impacto.

As gestões ambientais e sociais, muitas vezes, não estão ligadas ao sucesso econômico das empresas, mas são estritamente necessárias de serem observadas. Para as empresas alcançarem a sustentabilidade tem se discutido incansavelmente tanto estrategicamente (Hart, 1995, 1997; Roome, 1998), quanto instrumentalmente (Schaltegger Burritt, 2000; Bennet e James, 1999), pois o desempenho econômico só pode melhorar se simultaneamente forem observados o desempenho ambiental e o social (FIGGE et al., 2002, tradução nossa).

A falta de integração na relação entre o meio ambiente, o desempenho social da empresa e o desempenho econômico é um grande obstáculo para o crescimento. Com base em estudos empíricos que se referem à essa correlação, mas não a causalidade entre medidas ambientais e sociais e do sucesso econômico é que Figge et al., (2002, tradução nossa) confirmam essa análise, através de seus estudos apresentados nessa área e corroborando Pava e Krausz, 1996; Griffin e Mahon, 1997; Wagner, 2001; Schaltegger e Synnestvedt, 2002, ora citados pelo mesmo.

\subsection{VISÃO ESTRATÉGICA: TRIPÉ DA SUSTENTABILIDADE (TRIPLE BOTTON LINE)}

Dryzek (1997, p.129) apud Gerlach [200- tradução nossa] argumenta que o crescimento econômico deve ser ambiental e socialmente justo para as atuais e futuras gerações. E, ampliando esse conceito, acredita que o desenvolvimento sustentável, deve ser compreendido em seus três aspectos amplamente aceitos, isso ao considerar também análise de Brand e Jochum (2000, p.175, tradução nossa ), no que se refere também à dimensão econômica, social e ecológica.

O modelo de criação de valor sustentável de uma organização proposto por Hart e Milstein (2004) baseia-se não somente no objetivo econômico/financeiro de obtenção de lucro, mas também em que uma organização deve preocupar-se com o meio ambiente, no que diz respeito aos impactos que possam causar à natureza, devido às suas atividades, procurando evitar a degradação ambiental, bem como a responsabilidade social, na perspectiva de geração de emprego e renda para as famílias que dela dependem para seu bem estar econômico.

Neste contexto, o modelo proposto por Hart e Milstein (2004) constitui-se de um tripé no qual cada parte de uma organização deve estar intrinsecamente ligada para que seja reconhecida como efetivamente sustentável no que diz 
respeito aos aspectos ambientais, sociais e econômico/financeiros, observando em suas atividades todo o ciclo de vida do produto, desde o início até a sua finalização que implica em seu descarte, pós-utilização pelo consumidor final (HART e MILSTEIN, 2004).

Também o conceito do TPL - TRIPLE BOTTON LINE, assim conhecido como o tripé da sustentabilidade, conforme Moreira (2014) tem como objetivo uma gestão sustentável que visa reduzir impactos ambientais, gerar riqueza e valor para as organizações, atendendo aos anseios sociais quanto ao seu objetivo: people, planet and profit. People refere-se ao tratamento das pessoas pela empresa (sustentabilidade social); planet trata-se do meio ambiente (sustentabilidade ambiental); e profit diz respeito aos resultados, lucro ou prejuízo de uma organização (sustentabilidade econômico / financeira). Confirmando essa questão Matias (2007b, p.262) argumenta que os "aspectos ambientais, sociais e econômicos são importantes determinantes para o sucesso e sustentabilidade empresarial".

Esses aspectos da sustentabilidade, baseados no tripé supracitado foram desenvolvidos por John Elkington na década de 90, quando da apresentação de seu livro Cannibals with forks - the triple botton line of 21 st century business, aceitas como os pilares da sustentabilidade originalmente difundida, já comentado anteriormente na Introdução deste trabalho de pesquisa.

Elkington (2012) em sua mais recente reedição, diz que em relação à forma de avaliar o pilar ambiental da sociedade, algumas questões devem ser levantadas pelos executivos, tais como: observar quais formas de capital natural serão afetadas pelas operações da organização de modo a saber se o equilíbrio da natureza pode ou deverá ser comprometido de forma significativa.

\subsection{TOMADAS DE DECISÕES}

Tomar decisões faz parte da rotina empresarial. Diariamente todas as pessoas são expostas a situações nas quais se deve optar por um, ou outro caminho a seguir, considerando os possíveis impactos decorrentes dessa decisão.

De acordo com Braga (1987), os estudos teóricos e as pesquisas acerca do processo decisório têm obtido cada vez mais atenção. Para a autora, isso ocorre "principalmente porque este parece ser um aspecto fundamental dos papéis de liderança e é, também, muito relevante para um efetivo desempenho administrativo e organizacional".

O autor ainda cita Szilagyi e Wallace (1980), que apontam três diferentes níveis de decisões nas organizações: individuais, nos quais os indivíduos possuem objetivos próprios; de grupo, onde se buscam consensos relativos a normas de produção; e, por último, em níveis mais altos, por meio dos quais o processo decisório estabelece metas e estratégias organizacionais que permitem alcançá-las. Angeloni (2003) alerta que o processo decisório é afetado de forma significativa pela visão de cada um, na medida em que "diferentes pessoas diante de um mesmo fato tendem a interpretá-lo de acordo com seus modelos mentais, que as levam a percebê-lo de forma diferente". Nesse sentido, ela destaca a importância de o decisor 
buscar estratégias para amenizar essa interferência.

O decisor deve ter a consciência de que o maior desafio não é o de obter os dados, as informações e os conhecimentos, mas sim a aceitação de que, no processo de codificação/decodificação, as distorções ocorrem e que existem formas para amenizá-las (ANGELONI, 2003, p. 19).

Peter Drucker (2002) define a decisão como o desenvolvimento do raciocínio com foco na escolha entre diferentes cursos de ação onde, raramente, existe o certo e o errado. Uma decisão é desenvolvimento de um raciocínio. É uma escolha entre alternativas. Raramente é uma opção entre o certo e o errado. $\mathrm{Na}$ melhor das hipóteses é uma escolha entre o "quase certo" e o "provavelmente errado" - porém, muito mais frequentemente, é uma escolha entre dois cursos de ação, não sendo nenhum deles mais certo do que o outro (DRUCKER, 2002, p.119).

"As decisões estratégicas são orientadas para o futuro, com ramificações em longo prazo", defende Wright (2011). Assim, as decisões estratégicas requerem comprometimento.

Para Shimizu (2006), o processo de decisão de uma organização deve ser estruturado e resolvido de modo formal, detalhado, consistente e transparente, tendo em vista que os problemas que demandam decisões são amplos e complexos, envolvem riscos e incertezas, e envolvem a opinião e a participação de muitas pessoas. De acordo com o autor, para a organização, não é interessante ter apenas a melhor decisão no momento, mas, também, conhecer as outras alternativas possíveis.

\section{CONCLUSÃO}

O assunto abordado nesta discussão, com certeza, não é novidade na literatura da área de Administração e da Logística, mas os diversos estudos sobre o tema revelam claramente a sua importância para a pesquisa acadêmica e sua aplicação nas organizações.

A integração entre o Planejamento Estratégico Empresarial e o Planejamento Estratégico Logístico são extremamente significativos para a obtenção de vantagem competitiva pelas organizações, pois contribui para uma coordenação e controle mais fundamentados e precisos na implantação dos objetivos estratégicos e metas planejadas. No levantamento, entretanto, é possível verificar que, apesar dos conceitos e indicações dos elementos que influenciam o processo de integração da estratégia de negócios com a estratégia de logística, toda cadeia de suprimentos está ligada a estratégica.

Implantar um processo de planejamento, elaborar um plano estratégico, efetivar as mudanças e colocar em prática a administração participativa são tarefas complexas e de grande dificuldade. Muitos são os enfoques conceituais, diversas são as metodologias, inúmeras são as técnicas passíveis de se adotar. De todas as alternativas de enfoques, metodologias e técnicas, há sempre uma mais adequada à empresa em questão. As empresas que tentarem executar essas tarefas sem o conhecimento técnico necessário dificilmente terão sucesso. Por isso a pesquisa veio para contribuir com o capital intelectual das organizações. O estudo apresentado neste trabalho evidencia a 
importância do planejamento estratégico aliado à sustentabilidade. Isso faz com que ocorra um processo de integração entre essas partes, que quando transformados em projetos nas organizações irá levá-la a obter seu diferencial entre as demais, proporcionando-lhe vantagem competitiva frente ao mercado globalizado.

\section{REFERÊNCIAS}

ANGELONI, M. T. Elementos intervenientes na tomada de decisão. Ci. Inf., Brasília, v. 32, n. 1, p. 17-22, jan./abr. 2003. Disponível em: http://www.scielo.br/pdf/ci/v32n1/15969.pdf. Acesso em 17 mai. 2011.

BALLOU, R. H. Logística Empresarial: transportes, administração de materiais e distribuição física. 1. ed. São Paulo: Atlas, 2009.

BALLOU,RH Gerenciamento da cadeia de suprimentos/logística empresarial [recursoeletrônico] / Ronald H. Ballou ; tradução Raul Rubenich. - 5. ed. - Dadoseletrônicos. - Porto Alegre : Bookman, 2006/2007

BRAGA, N. O processo decisório em organizações brasileiras. Revista de Administração Pública, Vol. 21, No. 03. 1987. Disponível em:

<http://bibliotecadigital.fgv.br/ojs/index.php/rap/articl e/view/9747/8772>. Acesso em: 28 out 2013.

CARVALHO. F., Práticas de planejamento estratégico e sua aplicação em organização do terceiro setor. 2004. p, 207. Dissertação (Mestrado). Universidade de São Paulo faculdade de economia, administração e contabilidade departamento de administração programa de pós-graduação em administração. São Paulo, 2004.

\section{DRUCKER, 1997 - Administrando para o futuro}

DRUCKER, P. F. O Melhor de Peter Drucker: a administração; São Paulo. Nobel, 2002

FIGGE, Frank; HAHN, Tobias; SCHALTEGGER, Stefan, WAGNER, Marcus. The Sustainbility Balanced Scorecard-Linking Sustainability Management to Business Strategy. Business Strategy and the environment. 11, 269-284 (2002) Published online in Wiley InterScience (www.interscience.wiley.com). DOI: 10.1002/bse.339.
GERBER, Michael E. (2004). Empreender: fazendo a diferença. São Paulo: fundamento educacional.

Griffin, JJ e Mahon, JF (1997). O Desempenho Social Corporativo e o Debate do Desempenho Societário Corporativo: Vinte e Cinco Anos de Pesquisa Incomparável. Negócios e Sociedade, 36, 5-31.

HART, Stuart L.; MILSTEIN, Mark B. Criando valor sustentável. RAE - Revista de Administração de Empresas. Especial A. M. E: Artigo originalmente publicado na Academy os Management Executive, v. 17, n. 2, p. 56-69, mai 2003.

KOTLER, Philip \& KELLER, Kevin Lane (2006). Administração de Marketing. Ed. Pearson Education. 12. ed. São Paulo: Pearson Education.

KOTLER, Philip. Administração de marketing: análise, planejamento, implementação e controle. 2. ed. São Paulo: Editora Atlas, 1992.

LAKATOS, Eva Maria; MARCONI, Marina de Andrade. Metodologia Do Trabalho Científico. Andrade Marconi/ Lakatos- Editora Atlas S.A.- 2001-

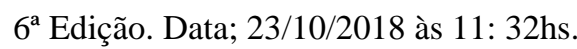

MATIAS, Alberto Borges. Finanças coorporativas de curto prazo: Gestão do valor do capital de giro, Volume 1. São Paulo: atlas,2007

MINTZBERG, Henry; AHLSTRAND, Bruce; LAMPEL, Joseph. (2006). Safári de Estratégia: um roteiro pela selva do planejamento estratégico. Porto Alegre: ed. Bookman.

MOREIRA, H. S. A.; MOREIRA, M. A.; CASTRO SILVA, W. A. Dez anos de pesquisa em empreendedorismo apresentados nos Enanpads de 2003 a 2012: análise dos autores engajados na área. Revista de Empreendedorismo e Gestão de Pequenas Empresas, v. 3, n.1, p. 33-55, 2014.

MOREIRA, Hudson Soares Athayde. Gestão empreendedora e fatores de sustentabilidade financeira do pequeno varejo supermercadista da região metropolitana de Belo Horizonte. 2014. 144 p. Dissertação (Mestrado) - Curso de Administração, Pós-graduação em Administração, Faculdade Novos Horizontes, Belo Horizonte, 2014.

NOVAES, Antônio G. Logística e Gerenciamento da Cadeia de Distribuição: estratégia, operação e avaliação. Rio de Janeiro: Campus. 2004.

Pava, ML e Krausz, J. (1996). A associação entre responsabilidade social corporativa e desempenho financeiro: o paradoxo do custo social. Jornal de Ética nos Negócios, 15, 321-57 
POZO, J.I.Humana mente: el mundo, la conciencia y la carne. Madrid: Morata, 2001.

SCHALTEGGER, S. e BURRITT, R. (2000). Contabilidade Ambiental Contemporânea. Questões, Conceitos e Práticas. Greenleaf, Sheffield.

SCHUMPETER, Joseph Alois. Teoria do desenvolvimento econômico: uma Cultural, 1997. 238 p.

SCHUMPETER, 1982, p. 56) - Capitalismo, Socialismo e Democracia (1942)

SHIMIZU, T. Decisão nas organizações. 2 ed. São Paulo: Atlas, 2006.

SLACK, Nigel, CHAMBERS,Stuart, JOHNSTON, Robert - Administração da Produção: ATLAS, $2^{\text {a }}$ edição de 2002

SZILAGYI, A. D., Jr.; WALLACE, M. J., Jr. Organizational behavior and performance. 2. ed. Santa Monica, California, Goodyear Publishing, 1980. p. 401

TRIVIÑOS, A. N. S. Introdução à pesquisa em ciências sociais: a pesquisa qualitativa em educação. São Paulo: Atlas, 1987.

WRIGHT, P. L. Administração estratégica: conceitos. 1 ed. São Paulo: Atlas, 2011.

WHITTINGTON, Richard. (2004). Estratégia após o modernismo: recuperando a prática. Rae - revista de administração de empresas. V. 44, n. 04, out a dez.
Jhuly Martins Magalhães

Tecnóloga em Logística (UninCor).

Doge Palhares Júnior

Mestre em Administração (UNIHORIZONTES).

Docente da Universidade Vale do Rio Verde -

UninCor.

Sérgio Ricardo Silva Magalhães

Pòs-Doutor em Educação (UFLO) . Docente da

Universidade Vale do Rio Verde - UninCor.

Letícia Rodrigues da Fonseca

Doutora em Administração (MACKENZIE).

Docente da Universidade Vale do Rio Verde -

UninCor.

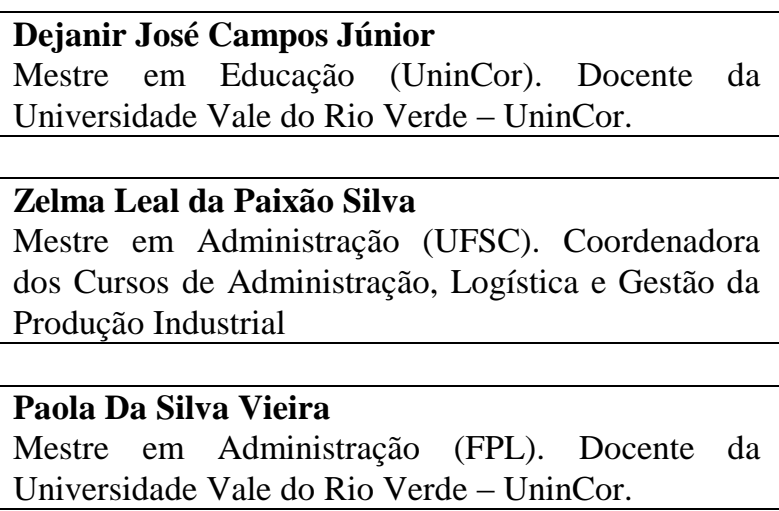

